\title{
IDENTIFICATION OF PROMINENT CRITERIAS IN THE SELECTION OF NEW GENERATION SMARTPHONES: AN APPLICATION IN ANADOLU UNIVERSITY
}

\author{
DOI: 10.17261/Pressacademia.2018.931 \\ PAP- V.7-2018(84)-p.442-448 \\ Haldun Colak ${ }^{1}$, Celal Hakan Kagnicioglu² \\ ${ }^{1}$ Anadolu University, İktisadi ve İdari Bilimler Fakültesi, Eskişehir, Turkey. \\ halduncolak@anadolu.edu.tr, ORCID: 0000-0003-4369-6063 \\ ${ }^{2}$ Anadolu Üniversitesi, İşletme Fakültesi, Eskişehir, Türkiye \\ chkagnic@anadolu.edu.tr, ORCID: 0000-0001-7164-3538
}

\section{To cite this document}

Colak, H., Kagnicioglu, C. H. (2018). Identification of prominent criterias in the selection of new generation smartphones: an application in Anadolu University. PressAcademia Procedia (PAP), V.7, p.442-448

Permemant link to this document: http://doi.org/10.17261/Pressacademia.2018.931

Copyright: Published by PressAcademia and limited licenced re-use rights only.

\begin{abstract}
Purpose- The purpose of the current study is to weight utilitarian and hedonic criterias affecting the customer's new generation smartphone selection and to array alternatives at the selection point. By appealing litrerature review and academician opinions, 4 main criterias and 14 subcriterias are specified and 4 brand that have the highest market share in Turkey are evaluated as alternatives at the study.

Methodology- An integrated AHP-VIKOR approach is used for the analysis. With the data collected by the AHP questionnaire, priorities belonged to all main and subcriterias are specified. Then by using these priorities, Brands are sorted with VIKOR method and criterias becoming prominent at the decision point are specified.

Findings- From main criterias, Product Aspects seems to be the most important criteria for the customers. When looked over subcriterias, Convenience, Brand Effect, Usage Benefit, Enjoyment, Hardware and Software Properties subcriterias are prominent at the customer's decision point.

Conclusion- Within the frame of contributory models, current study presents a perspective which is genuine in the field by taking both functional and other criterias affecting smartphone selection in the scope.
\end{abstract}

Keywords: Multi criteria decision making, AHP, VIKOR, smartphone selection.

Jel Codes: C02, M31

TÜKETICILERIN YENI NESIL AKILLI TELEFON TERCIHINDE ÖNE ÇIKAN KRITERLERIN BELIRLENMESI: ANADOLU ÜNIVERSITESINDE BIR UYGULAMA

\section{ÖZET}

Amaç- Mevcut çalışmanın amacı tüketicilerin yeni nesil akıllı telefon seçimlerinde etkili olan fayda ve haz temelli kriterlerin ağırlıklandıııması ve seçim noktasında alternatiflerin sıralanmasıdır. Literatür taraması ve akademisyen görüşlerine başvurularak toplamda 4 ana kriter ve 14 alt kriter belirlenmiş ve Türkiye Pazar payı en yüksek olan 4 marka çalışmada değerlendirilmiştir.

Yöntem- Analiz için bütünleşik AHP-VIKOR yöntemi uygulanmıştır. AHP anketiyle toplanan veriler neticesinde bütün ana ve alt kriterlere ait öncelikler belirlenmiştir. Ardından bu öncelikler kullanılarak VIKOR yöntemi ile markalar sıralanmış ve öne çıkan kriterler belirlenmiştir. Bulgular- Ana kriterlerden Ürün Özellikleri tüketiciler için en önemli kriter olmaktadır. Alt kriterler incelendiğinde ise Uygunluk, Markanın Etkisi, Kullanım Faydası, Keyif Alma ve Yazılım ve Donanım Özellikleri alt kriterleri öncelikli olmaktadır.

Sonuç- Mevcut çalışma beslendiği modeller çerçevesinde akıllı telefon tercihinde ürün özellikleri dışında diğer kriterleri de kapsamında tutarak bu alanda özgün bir bakış açısı sunmaktadır.

Anahtar Kelimeler: Çok kriterli karar verme, AHS, VIKOR, akıllı telefon seçimi. Jel Codes: C02, M31 


\section{GíRiş}

Akıllı telefon teknolojisi hızlı bir şekilde gelişmekte ve iletişim kurma, bilgiye ulaşma, eğlenme ve günlük diğer aktivitelerin yürütülmesinde kullanıılara yeni yollar sunmaktadır (Park vd., 2013). Tüketiciler nerede olurlarsa olsunlar bilgiye anlık ulaşıp paylaşımda bulunabilir, birçok uygulama sayesinde iyi vakit geçirebilir ve akıllı telefonun sağladığı çok çeşitli imkanlarla çevreleriyle iletişim kurabilirler (Gao, Yang ve Krogstie, 2015). Bu noktada geliştirilen yeni işletim sistemleri, çok sayıda uygulama ve üreticiler arasındaki rekabet akıllı telefonları tüketiciler için vazgeçilmez hale getirmiştir (Lau, Lam ve Cheung, 2016). Ancak bilgi ve teknolojideki gelişmeler tüketicilere çok sayıda alternatif sunduğu için, satın alma noktasında karar verme zorlaşmaktadır (Erinci ve Sulak, 2014). Bu noktada tüketicinin akıllı telefon tercihinde etkili olan kriterlerin belirlenmesi önem kazanmaktadır. Mevcut çalışmanın amacı çok kriterli karar verme yöntemlerinden Analitik Hiyerarşi Süreci (AHS) ve VIKOR kullanarak tüketicinin yeni nesil akıllı telefon tercihinde etkili olan kriterlerin belirlenmesi ve en iyi alternatifin ortaya konmasıdır. Bu doğrultuda, teknoloji kabul teorisi, inovasyon yayılma modeli ve birleştirilmiş teknoloji kullanım ve kabul teorileri kapsamında incelenen ve de akademisyen görüşleri ile elde edilen kriterler araştırma kapsamında analiz edilmiştir.

\section{LITERATÜR ANALIZi}

Tüketicilerin akıllı telefon tercihine yönelik çalışmalar incelendiğinde AHS yöntemini kullanarak karar noktasında etkili olan kriterleri belirleyen az sayıda çalışmaya rastlanmıştır. Bayhan ve Bildik (2014) AHS yöntemi ile tüketicilerin akıllı telefon tercihlerinde somut özelliklerin yanında soyut bulanık özellikleri de ekleyerek akıllı telefonun satın alınmasına yönelik kriterleri değerlendirmişlerdir. Kecek ve Yüksel (2016) ise AHS ve PROMETHEE yöntemlerini kullanarak akıllı telefon tercihinde ekili olan kriterleri telefonların fonksiyonel özelliklerine göre değerlendirerek en iyi alternatifi ortaya koymuşlardır. Tochukwu (2014) akılı telefonları işletim sistemi, ekran büyüklüğü ve kamera özellikleri kriterlerine göre karşılaştırarak AHS yöntemiyle en iyi alternatifi belirlemiştir. Benzer şekilde Chakraborty vd., (2015) AHS yöntemini kullanarak akıllı telefonların sadece fonksiyonel özelliklerini karşılaşıııı, akıllı telefonlarda öne çıkan temel özellikleri ağırlıklandırmıştır. Bu çalışmalarda belirlenen kriterlerin genellikle akıllı telefonların fonksiyonel özelliklerine dayandırıldığı ve akıllı telefonların tercih edilmesi noktasında tüketicilerin hedonik, sosyal ve psikolojik faydalarını tanımlayacak olan kriterlerin dikkate alınmadığı gözlemlenmiştir. Bu kriterler çoğunlukla yeni teknolojik ürünler olarak akıllı telefonların kabulü, akıllı telefon kullanımına yönelik tutum ve satın alma niyeti üzerine yoğunlaşan çalışmalarda ele alınmaktadır. Bu çalışmalarda genellikle teknoloji kabul modeli (TKM), inovasyon yayılma modeli (iYM) ve bütünleşik teknoloji kullanım ve kabul teorisine ait faktörlerin incelendiği saptanmıştır.

Literatürde yer alan birçok çalışmada ise yeni teknolojiler olarak akıllı telefonların kabulü, satın alma niyeti, tutum, kullanım memnuniyeti ve tatmini ele alınmıştır. Ayrıca akıllı telefonların tercih edilmesi noktasında tüketicilerin hedonik, sosyal ve psikolojik faydalarını tanımlayacak olan kriterler literatürün bu boyutunda ele alınmaktadır. Bu çalışmalarda AHS yöntemi kullanılmasa da dayandıkları temel modeller olan teknoloji kabul modeli (TKM), İnovasyon yayılma modeli (iYM) ve bütünleşik teknoloji kullanım ve kabul teorisinden elde edilen faktörler mevcut çalışmada intiyaç duyulan ana ve alt kriterlerin belirlenmesinde kullanılmıştır. Bu bağlamda (Chun vd., 2012) akıllı telefonların benimsenmesini sosyal etki, algılanan teknik özellikler, öz benlik, hazsal eğlence ve faydalı kullanım faktörlerini bütünleștirip teknoloji kabul modelini kullanarak akıllı telefon kabul niyetini ölçmüşlerdir. Lau, Lam ve Cheung (2016) ise akıllı telefon satın alma niyetini TKM kriterleri, algılanan haz, algılanan değer ve sübjektif normlarla bütünleştirilmiş bir model kullanarak incelemiştir. Hsiao (2013) android akıllı telefonların kabulü ve mobil servis satın alma niyetini, akıllı telefonların yazılım ve donanım özelliklerinin yanına tasarım estetiği ve algılanan değer boyutlarını da ekleyerek mobil internet kullanan ve kullanmayanlar arasında akıllı telefonların kabulündeki farklılıklar ortaya koymuştur. Bir diğer çalışmada ise Kim (2014) TKM ve bütünleşik teknoloji kullanım ve kabul teorileri çerçevesinde akıllı telefona yönelik algılanan kullanım kolaylığı, kullanım faydası, ilişkiler ve oyun özelliklerinin tutum üzerine etkisi ve sonrasında kullanım niyetine olan etkilerini incelemiştir. Park ve Chen (2007) doktorlar ve hemşirelerin akıllı telefon kabullerinde etkili olan motivasyon unsurlarını öz yeterlilik, TKM ve iYM çerçevesinde açıklayarak akıllı telefon kullanımına yönelik davranışsal tutumun algılanan kullanım kolaylığı ve algılanan faydadan yoğun bir şekilde etkilendiği sonucuna ulaşmışlardır. Literatür taraması sonucu belirlenen ana ve alt kriterler ve bunlara karşılık gelen fayda boyutları Tablo 1 , Tablo 2 ve Tablo 3'te gösterilmiștir. 
Tablo 1: Ana ve Alt Kriterler ile Faydalanılan Çalışmalar

\begin{tabular}{|c|c|c|}
\hline Ana Kriterler & Alt Kriterler & İlgili Çalışmalar \\
\hline İnovatif Ürün & $\begin{array}{l}\text { Eşsiz Olma } \\
\text { Nispi Avantaj } \\
\text { Ürün Sonuçlarının Gözlemlenebilir Olması } \\
\text { Uygunluk }\end{array}$ & $\begin{array}{l}\text { (Mannan ve Haleem, 2017; Wu vd., } \\
\text { 2016; Hsiao, 2017; Kim, 2016; Gao } \\
\text { vd., 2015) }\end{array}$ \\
\hline Sosyal Etki & $\begin{array}{l}\text { Çevrenin Onayı } \\
\text { İnternette Yer Alan Kullanıcı Tavsiyeleri } \\
\text { Kişisel İmaj } \\
\text { Markanın Etkisi }\end{array}$ & $\begin{array}{l}\text { (Lu vd.., 2017; Chun vd., 2012; Yu } \\
\text { vd., 2017; Park vd., 2013; Moon ve } \\
\text { Chang, 2014; Toufani vd. 2017; } \\
\text { Jung 2014; Lau vd., 2016; Kim vd., } \\
\text { 2014; Chen vd., 2014; Hsiao, 2017; } \\
\text { Denghani, 2018; Arif vd., 2016; } \\
\text { Kim, 2017; Gao vd., 2015; Haba } \\
\text { vd., 2017) }\end{array}$ \\
\hline Ürün Özellikleri & $\begin{array}{l}\text { Tasarım Estetiği } \\
\text { Yazılım ve Donanım Özellikleri } \\
\text { Fiyat }\end{array}$ & $\begin{array}{l}\text { (Yu vd., 2017; Moon ve Chang, } \\
\text { 2014; Toufani vd., 2017; Hsiao ve } \\
\text { Chen, 2018) }\end{array}$ \\
\hline Ürün Faydas1 & $\begin{array}{l}\text { Kullanım Kolaylığı } \\
\text { Kullanım Faydası } \\
\text { Keyif Alma }\end{array}$ & $\begin{array}{l}\text { (Yu vd., 2017; Kim vd., 2017; Kim, } \\
\text { 2014; Lau vd., 2016; Park ve Chen, } \\
\text { 2007; Kim vd., 2014; Haba vd., } \\
\text { 2017) }\end{array}$ \\
\hline
\end{tabular}

Tablo 2: Bazı Ana ve Alt Kriterlere Karşılık Gelen Fayda Boyutları|

\begin{tabular}{|l|l|l|}
\hline Ana Kriterler & Alt Kriterler & $\begin{array}{l}\text { Kriterin Yansittığı Fayda } \\
\text { Boyutu }\end{array}$ \\
\hline Sosyal Etki & $\begin{array}{l}\text { Çevrenin Onayı } \\
\text { Kullanıı Tavsiyeleri }\end{array}$ & $\begin{array}{l}\text { Sosyal, Duygusal, Psikolojik } \\
\text { (Arif vd.., 2016; Lee, 2014; Kim } \\
\text { vd., 2014) }\end{array}$ \\
\hline & Kişisel İmaj & $\begin{array}{l}\text { Hedonik, Psikolojik (Filieri ve } \\
\text { Lin, 2017; Liu ve Yu, 2016) }\end{array}$ \\
\hline & $\begin{array}{l}\text { Tasarım Estetiği } \\
\text { Yazılım ve Donanım Özellikleri }\end{array}$ & $\begin{array}{l}\text { Hedonik, (Chun vd., 2012; Filieri } \\
\text { ve Lin, 2017) }\end{array}$ \\
\hline Ürün Faydası & $\begin{array}{l}\text { Kullanım Kolaylığ1 } \\
\text { Kullanım Faydası }\end{array}$ & $\begin{array}{l}\text { Hedonik, Duygusal, Fonksiyonel, } \\
\text { Psikolojik (Toufani vd., 2017; } \\
\text { Kim ve Shin, 2015) }\end{array}$ \\
\hline Ürün Faydası & Keyif Alma & $\begin{array}{l}\text { Hedonik, Psikolojik (Jung, 2014; } \\
\text { Lu vd., 2017) }\end{array}$ \\
\hline
\end{tabular}

"Tablo 1" de literatür taraması sonucu belirlenen ana ve alt kriterler gösterilmektedir. "Tablo 2" ise hangi kriterin hangi fayda boyutuna karşılık geldiğini göstermektedir. "Tablo 1" de belirlenen kriterler yoğunlukla IYM, TKM ve birleştirilmiş teknoloji kullanım ve kabul modellerine dayandırılan çalışmalardan elde edilmiştir. Bu çalışmalar ışığında İnovatif Ürün, tüketici tarafından yeni olarak görülen bir obje, uygulama ya da düşüncedir ve "Tablo 1"de verilen boyutlardan oluşmaktadır. Ürün faydası üründen alınan toplam faydayı ifade ederken TKM'e göre kullanım kolaylığı ve kullanım faydası boyutlarından oluşmaktadır. Bunun yanında güncel çalışmalarda keyif almanın yeni boyut olarak modele eklendiği görülmektedir. Sosyal etki kişinin, çevresinin teknolojik ürünü kullanması gerektiğine yönelik inancını ifade ederken, bu etkiyi çevrenin onayı, ağızdan ağıza iletişim, ürünün kişinin imajını yansıtması ve marka imajı boyutları oluşturmaktadır. Ürün özellikleri ise akıllı telefonun yazılım ve donanım özelliklerini kapsamaktadır. Bunun yanında tüketicinin psikolojik ve hedonik faydasını açıklaması açııından tasarım estetiği geçmiş çalışmalarda ayrıca incelenmektedir. Fiyat ise akademisyen görüşleri neticesinde ürün özellikleri boyutuna eklenmiştir. Son olarak alternatifler ise Türkiye akıllı telefon pazarında en çok pazar payına sahip ilk 3 marka (Samsung \% 40.3, Apple \% 15.4, General Mobile \% 13.4) ve diğerleri olarak çalışmada yer bulmuştur (Passport, 2017). 
Dolayısıyla mevcut çalışma bir köprü işlevi görerek ÇKV yöntemleri ile akıllı telefon tercihinde etkili olan faktörlerin belirlenmesinde fonksiyonel, psikolojik, sosyal ve hedonik faydaya yönelik faktörleri çalısmada adı geçen teoriler kapsamında birleştirerek, alan yazında akıllı telefon tercihine yönelik AHS ile yapılmış önceki çalışmalardan ayrıımaktadır.

\section{TASARIM VE YÖNTEM}

Mevcut çalışmanın amacı tüketicilerin akıllı telefon tercihinde etkili olan kriterlerin belirlenmesi ve en iyi alternatifin seçilmesidir. Bu bağlamda tüketici herhangi bir alternatif üzerinde tercihte bulunurken neden bu kararı verdiği, belirlenen kriterler çerçevesinde açıklanmaya çalışılııştır. Dolayısıyla mevcut çalışma uygulamalı keşifsel bir çalışmadır. Çalışmada amaca yönelik olarak;

$$
\begin{aligned}
& \text { - } \quad \text { Tüketicilerin akıllı telefon tercihlerinde etkili olan kriterlerin hangilerinin öncelikli olduğu, } \\
& \text { - } \quad \text { Öncelikleri belirlenen kriterler çerçevesinde hangi alternatifin öne çıktığı, } \\
& \text { - } \quad \text { Alternatifler değerlendirilirken belirlenen kriterlerde farkıılaşmalar olup olmadığı soruları üzerinde durulmaktadır. }
\end{aligned}
$$

Çalışmanın anakütlesini yeni nesil akıllı telefon kullanıcıları oluşturmaktadır. Bu noktada kolayda örnekleme yöntemi uygulanarak Anadolu Üniversitesi çalışanları ve öğrencileri araştırma kapsamında ele alınmıştır. Bu bağlamda veriler analitik hiyerarşi sürecinde (AHS) kullanılan özel AHS ölçeğiyle hazırlanmış anket ile toplanmıştır. Veriler 1 Şubat-10 Mart tarihleri arasında elden ve de mail yoluyla katııımcılara uygulanmıştır. Verilerin analizinde ise ÇKV yöntemlerinden olan Analitik Hiyerarşi Süreci (AHS) ile VIKOR kullanılmıştır. Çalışmada adı geçen kriterler, bu kriterlere bağlı alt kriterler ve alternatiflere bağlı önceliklerin belirlenmesi için AHS yöntemi uygulanmıştır. Çok kriterli karar verme yöntemlerinden birisi olan AHS (Analitik hiyerarşi süreci) karmaşık karar problemlerinde alternatif ve kriterlere göreceli öncelik değerleri verilerek en iyi alternatifi ortaya koymaya çalışan bir karar verme işlemidir (Timor, 2011). Seçim problemlerinde amaç en iyi alternatifi bulmak iken sıralama problemlerinde amaç bütün alternatifleri en iyiden en kötüye doğru sıralamaktır. Bu noktada VIKOR yöntemi alternatifler arasından birden fazla sayıda ve aynı anda uygulanabilen kriterlerle ilişkili olarak en iyi tercihin seçilmesine imkan tanımaktadır (Kuzu, 2014). Kriter, alt kriter ve alternatiflere yönelik öncelik değerlerinin AHS ile belirlenmesinden sonra VIKOR yöntemi uygulanarak en iyi alternatif otaya konmuştur. AHS ve VIKOR yöntemleriyle analiz yapılabilmesi için Excell ve Super Decision paket programları kullanılmıştır.

Tüketici karar verme süreci, hem rasyonel hem de duygusal özelliklere sahip olan ve dolayısıyla akıllı telefon tercihi kapsamında düşünüldüğünde bilgi, iletişim, eğlence ve yeni teknolojilerin benimsenmesi gibi birçok tüketici ihtiyaçlarını betimleyecek boyutları içeren karmaşık bir yapıdır (Chun, Lee ve Kim, 2012). Bu noktada AHS karmaşık karar verme problemlerinde kullanılabilecek önemli yöntemlerden birisidir. AHS yöntemi belirlenen kriter, alt kriter ve alternatifler arasında A'nın B'ye göre ne kadar önemli olduğu sorusuna dayalı olarak ikili karşılaştırmalar yaparak önceliklerin belirlenmesini sağlamaktadır. En iyi alternatifi sıralama yaparak belirleyen VIKOR'da ise temel nokta birbirleri ile çelişen kriterler olduğunda en iyi alternatifin sıralama yapılarak seçilmesine odaklanmıştır. Dolayısıyla AHS ile belirlenen kriterlere göre en iyi alternatifin belirlenmesinde VIKOR yöntemi, AHS yöntemi ile gösterebileceği uyumdan dolayı çalışmada tercih edilmiştir.

\section{BULGULAR VE TARTIŞMA}

Her bir ana ve alt kriterin ikili karşılaştırmaları sonucu elde edilen öncelik değerleri, alt kriterlerin alternatifler bazında ikili karşılaştırmaları sonucu elde edilen öncelikleri ve VIKOR yönteminde başlangıç matrisinin verilerini oluşturacak global ağırlık değerleri sırasıyla "Tablo 3",

\begin{tabular}{|c|c|c|c|}
\hline \multicolumn{4}{|c|}{$\begin{array}{l}\text { Kriterler ve Alt } \\
\text { Kriterler }\end{array}$} \\
\hline İnovatif Ürün $(0,12)$ & Sosyal etki $(0,09)$ & Ürün Özellik. $(0,41)$ & Ürün Faydası $(0,38)$ \\
\hline Esssiz Olma $(\mathbf{0 , 1 4})$ & Cevrenin Onay1 $(0,28)$ & Tasarım Est. $(\mathbf{0 , 2 5})$ & Kullanım Kol. $(\mathbf{0 , 2 0})$ \\
\hline Nispi Avantaj $(\mathbf{0 , 2 4})$ & $\begin{array}{l}\text { İ.Yer.AdKultax. } \\
(\mathbf{0 , 2 3})\end{array}$ & Fiyat $(0,25)$ & Kullanım Fay. $(\mathbf{0 , 4 0 )}$ \\
\hline Ü,Son Göz Ol, $(0,28)$ & Markanin Etkisi $(0,19)$ & Yaz.Don.Özl. $(0,50)$ & Keyif Alma $(0,40)$ \\
\hline Uygunluk $(0,34)$ & Kișisel İmaj $(0,30)$ & & \\
\hline
\end{tabular}
"Tablo 4", ve "Tablo 5" de gösterilmiştir.

Tablo 3: Ana ve Alt Kriterlerin İkili Karşılaștırmaları Sonucu Elde Edilen Öncelik Değerleri 
Tablo 4: Alt Kriterlerin Alternatifler Bazında İkili Karșlaștırmaları Sonucu Elde Edilen Öncelik Değerleri

\begin{tabular}{|l|l|l|l|l|}
\hline & Apple & Samsung & General Mobile & Diğer \\
\hline Eșsiz Olma & 0,60 & 0,24 & 0,08 & 0,09 \\
\hline Nispi Avantaj & 0,57 & 0,26 & 0,08 & 0,09 \\
\hline Ü.Son_Göz.O1 & 0,60 & 0,22 & 0,09 & 0,09 \\
\hline Uygunluk & 0,46 & 0,32 & 0,10 & 0,12 \\
\hline Cevrenin Onay1 & 0,60 & 0,24 & 0,08 & 0,09 \\
\hline İ.Yer_L1.Kul.Tav. & 0,55 & 0,27 & 0,09 & 0,09 \\
\hline Markanın Etkisi & 0,63 & 0,23 & 0,07 & 0,07 \\
\hline Kișisel İmaj & 0,60 & 0,24 & 0,08 & 0,09 \\
\hline Tasarım Est. & 0,60 & 0,24 & 0,08 & 0,09 \\
\hline Fiyat & 0,45 & 0,26 & 0,14 & 0,14 \\
\hline Yaz_Don_özl. & 0,55 & 0,27 & 0,09 & 0,09 \\
\hline Kullanım Kol. & 0,46 & 0,30 & 0,12 & 0,11 \\
\hline Kullanım Fay. & 0,58 & 0,24 & 0,08 & 0,09 \\
\hline Keyif Alma & 0,61 & 0,23 & 0,08 & 0,08 \\
\hline
\end{tabular}

Tablo 5: Global Ağırlık Değerleri

\begin{tabular}{|l|l|l|l|l|}
\hline & İnovatif Ürün & Sosyal Etki & Ürün Özellikleri & Ürün Faydas1 \\
\hline Ăgrllklar & $\mathbf{0 , 1 2}$ & $\mathbf{0 , 0 9}$ & $\mathbf{0 , 4 1}$ & $\mathbf{0 , 3 8}$ \\
\hline Apple & 0,56 & 0,60 & 0,53 & 0,55 \\
\hline Samsung & 0,26 & 0,25 & 0,25 & 0,27 \\
\hline Gm & 0,09 & 0,07 & 0,11 & 0,09 \\
\hline Diğer & 0,1 & 0,08 & 0,11 & 0,09 \\
\hline & & & & \\
\hline
\end{tabular}

"Tablo 1" de gösterilen ana kriter, alt kriter ve alternatiflere ilişkin ikili karşılaştırmalar AHS yönteminin de kurucusu Thomas Saaty tarafından belirlenen ikili karşılaştırma ölçeği kullanılarak belirlenmektedir. Burada 1,3,5,7,9 sırasıyla eşit önem, orta düzeyde önem, ortadan daha fazla önem, kuvvetli düzeyde önem ve çok kuvvetli düzeyde önemi ifade etmektedir (Bayhan ve Bildik, 2014). 2,4,6,8 değerleri ise ara değerledir. Ana kriterlerin ikili karşılaştırma sonucunda Ürün Özellikleri 0.40, Ürün Faydası 0.38 , Sosyal Etki 0.10 ve İnovatif Ürün 0.10 değerlerini almıştır. Burada ana kriterler bazında incelendiğinde akılı telefon tercihinde tüketiciler için ürün özelliklerinin (yazııı ve donanım, fiyat, tasarım estetiği) daha öncelikli olduğu görülmektedir. Alt kriterler bazında incelendiğinde ise Uygunluk 0.34, Markanın Etkisi 0.31, Yazılım ve Donanım Özellikleri 0.41 , Kullanım Faydası 0.40 ve Keyif Alma 0.40 alt kriterlerinin daha öncelikli oldukları anlaşılmaktadır. Burada alt kriterlerin özelliklerine dikkat edilecek olunursa ana kriterler kapsamında belirlenmek istenen psikolojik, sosyal ve hedonik faydaların akıllı telefon tercihinde bir arada gösterilmesi sağlanmıştır. Alt kriterler marka bazında incelendiğinde büyük farklılaşmalara rastlanmamıştır. Pazar payları dikkate alındığında her ne kadar lider marka Samsung olsa da, çalışma kapsamında Apple'ın bütün karşılaştırmalarda tercih edilen marka olduğu anlaşılmaktadır. Bu noktada "Markanın Etkisi", "Keyif Alma”, "Kişisel İmajı Yansıtma", "Tasarım Estetiği” ve "Çevrenin Onayı" alt kriterleri Apple'ın tercih noktasında en öne çıktığı kriterler olmuştur. Benzer şekilde pazar payı en yüksek 3. marka olan Samsung birçok karşılaştırmada Diğer markalara göre daha düşük değerler almıştır. AHS algoritması gereği son karşılaştırma tablosuna göre bütün kriterler bazında ağılıklar sırasıyla (İnovatif Ürün, Sosyal Etki, Ürün Özellikleri, Ürün Faydası) Apple 0.54, Samsung 0.25, General Mobile 0.09 ve Diğer markalar 0.10 değerlerini almışlardır. AHS analizi sonucu elde edilen son ağırılılar bir sonraki adımda VIKOR yöntemi için başlangıç matrisinde kullanılacak değerleri yansıtmaktadır. VIKOR yöntemi AHS'de belirlenen ağırlıkları kullanarak en iyi alternatifi kriterler bazında sıralamaktadır. Bu noktada VIKOR sonuçlarına göre en iyi alternatif sıralaması Apple, Samsung, General Mobile ve Diğer markalar şeklinde olmuştur.

\section{SONUÇ, ÖNERILER VE KISITLAR}

Mevcut çalışmada tüketicinin akıllı telefon tercihini psikolojik, sosyal, hedonik ve fonksiyonel açılardan ele alan kriterler kullanılmıştır. Bu kriterlerin AHS-VIKOR yöntemiyle incelenerek en iyi seçimi ortaya koyulması, literatüre özgün bir katkı olarak düşünülmektedir. Her ne kadar çalışma kapsamında marka tercihinde tüketicilerin ana kriterler olarak ürün özelliklerini ön planda tuttuğu görülse de, pazar paylarıyla karşılaştııı ıığında alt kriterlerin ağırıkları marka tercihinde tüketicilerin farklı yönelimde olduğuna işaret etmektedir. Bu bulgu uygulayııılar için önem ifade edebilir. Apple kullanııılarının fiyat kriterini en az öneme sahip olarak değerlendirdiği, fakat diğer markaların tercihinde bu kriterin daha önemli olduğu anlaşılmaktadır. Markanın etkisi Apple'ın tercihinde en öne çıkan alt kriter olurken, diğer markaların tercihinde bu etki görece daha düşük olmaktadır. Benzer șekilde Uygunluk Apple’ın tercihinde en az önceliğe sahipken, Samsung için en öne çıkan kriter 
olarak görülmektedir. Bulgular ışığında marka tercih edilirken sadece ürüne yönelik özelliklerin önemli olmadığı, markaların marka değerlerini arttıracak çalışmalarda bulunmaları gerektiği anlaşılmaktadır. Her ne kadar AHS yöntem uygulaması olarak kolay olsa da, özellikle ana kriter, alt kriterler ve alternatiflerin sayısının fazla olması durumunda ikili karşılaştırmaların da sayısının artacağından verinin toplanmasında zorluklara neden olmaktadır. Bu husus veri toplanan katılımcılardan geri dönüş oranını düşürdüğü için mevcut çalışmanın en önemli kısıtı olmaktadır. Ayrıca yeni teknolojiler olarak akıllı telefonların ele alınmasında hangi grupların öncelikli olarak karar verdiği ve hangi alternatife yöneldiğine odaklanan çalışmalar daha açıklayıcı sonuçlara ulaşılmasında faydalı olacaktır. Markaların pazar paylarıyla kriterler bazında öncelikleri karşılaştırıldığında, tercih noktasında katılımcıların farklı bir yönelimde olduğu görülmektedir. Bu noktada belirlenen kriterlere yenileri eklenerek ve de en çok öne çıkan alt kriterler bileşenlerine ayrılarak ortaya çıkan farklılığın sebepleri daha detaylı analiz edilebilir. Bu da markalara tüketici tarafından tercih edilmeleri bağlamında hangi yönlerden eksik kaldıkları ve marka değerlerini yükseltmeleri açısından detaylı bir bakış açısı sağlayacaktır.

\section{REFERENCES}

Arif, I., Aslam, W., Ali, M. (2016). Students' dependence on smartphones and its effect on purchasing behavior. South Asian Journal of Global Business Research, 5(2), 285-302.

Bayhan, M., Bildik, T. (2014). Çok kriterli karar verme tekniklerinden analitik hiyerarşi süreciyle akıllı telefon seçimi. Uluslararası Alanya İşletme Fakültesi Dergisi, 6(3).

Chakraborty, S., Srivastava, S., Das, K. (2015). Application of Analytic Hierarchy Process (AHP) to prioritize the factors Indian consumers consıder while buying smart phones in India. International Journal of Advanced Technology in Engineering and Science., Volume No 03, Special Issue No. 01

Chen, C. C., Shih, H. S. (2014). A study of the acceptance of wearable technology for consumers: an analytical network process perspective. Int J Anal Hierarchy Process, 1-5.

Chun, H., Lee, H., Kim, D. (2012). The integrated model of smartphone adoption: hedonic and utilitarian value perceptions of smartphones among Korean college students. Cyberpsychology, Behavior, and Social Networking, 15(9), 473-479.

Dehghani, M. (2018). Exploring the motivational factors on continuous usage intention of smartwatches among actual users. Behaviour \& Information Technology, 37(2), 145-158.

Erinci, A. G. F., Sulak, H. (2014). Analitik hiyerarşi proses ile akıllı telefon seçimi. Süleyman Demirel üniversitesi iktisadi ve idari Bilimler Fakültesi Dergisi, 19(4).

Filieri, R., Lin, Z. (2017). The role of aesthetic, cultural, utilitarian and branding factors in young Chinese consumers' repurchase intention of smartphone brands. Computers in Human Behavior, 67, 139-150.

Gao, S., Yang, Y., Krogstie, J. (2015, March). The adoption of smartphones among older adults in China. In International Conference on Informatics and Semiotics in Organisations (pp. 112-122). Springer, Cham.

Haba, H., Hassan, Z., Dastane, O. (2017). Factors leading to consumer perceived value of smartphones and its impact on purchase intention.

Hsiao, K. L. (2013). Android smartphone adoption and intention to pay for mobile internet: Perspectives from software, hardware, design, and value. Library Hi Tech, 31(2), 216-235.

Hsiao, K. L. (2017). What drives smartwatch adoption intention? Comparing Apple and non-Apple watches. Library Hi Tech, 35(1), 186-206.

Hsiao, K. L., Chen, C. C. (2018). What drives smartwatch purchase intention? Perspectives from hardware, software, design, and value. Telematics and Informatics, 35(1), 103-113.

Jung, Y. (2014). What a smartphone is to me: understanding user values in using smartphones. Information Systems Journal, 24(4), $299-321$.

Kecek, G., Yüksel, R. (2016). Analitik hiyerarşi süreci (AHP) ve Promethee teknikleriyle akıllı telefon seçimi. Dumlupınar Üniversitesi Sosyal Bilimler Dergisi, (49), 46-62.

Kim, S. H. (2014). A study on adoption factors of Korean smartphone users: a focus on TAM (Technology Acceptance Model) and UTAUT (Unified Theory of Acceptance and Use of Technology). Advanced Science and Technology Letters, 57, 27-30.

Kim, D., Chun, H., Lee, H. (2014). Determining the factors that influence college students' adoption of smartphones. Journal of the Association for information Science and Technology, 65(3), 578-588.

Kim, K. J., Shin, D. H. (2015). An acceptance model for smart watches: Implications for the adoption of future wearable technology. Internet Research, 25(4), 527-541. 
Kim, Y., Kim, S., Rogol, E. (2017). The effects of consumer innovativeness on sport team applications acceptance and usage. Journal of Sport Management, 31(3), 241-255.

Kim, K. J. (2017). Shape and size matter for smartwatches: effects of screen shape, screen size, and presentation mode in wearable communication. Journal of Computer-Mediated Communication, 22(3), 124-140.

Kuzu, S. (2014). Vikor. Çok kriterli karar verme yöntemleri, 117-132.

Lau, M. M., Lam, A. Y., Cheung, R. (2016). Examining the factors influencing purchase intention of smartphones in Hong Kong. Contemporary Management Research, 12(2).

Liu, N., Yu, R. (2017). Identifying design feature factors critical to acceptance and usage behavior of smartphones. Computers in Human Behavior, 70, 131-142.

Lu, J., Liu, C., Wei, J. (2017). How important are enjoyment and mobility for mobile applications?. Journal of Computer Information Systems, 57(1), 1-12.

Mannan, B., Haleem, A. (2017). Understanding major dimensions and determinants that help in diffusion \& adoption of product innovation: using AHP approach. Journal of Global Entrepreneurship Research, 7(1), 12.

Moon, B. C., Chang, H. (2014). Technology acceptance and adoption of innovative smartphone uses among hospital employees. Healthcare informatics research, 20(4), 304-312.

Park, Y., Chen, J. V. (2007). Acceptance and adoption of the innovative use of smartphone. Industrial Management \& Data Systems, 107(9), 1349-1365.

Park, N., Kim, Y. C., Shon, H. Y., Shim, H. (2013). Factors influencing smartphone use and dependency in South Korea. Computers in Human Behavior, 29(4), 1763-1770.

Timor, M. (2011). Analitik hiyerarşi prosesi. Türkmen Kitabevi.

Tochukwu, U. L. (2014). Using the analytic hierarchy process for choosing a best smartphone. Doi, 10(2.1), 3788-7040.

Toufani, S., Stanton, J. P., Chikweche, T. (2017). The importance of aesthetics on customers' intentions to purchase smartphones. Marketing Intelligence \& Planning, 35(3), 316-338.

Yu, J., Lee, H., Ha, I., Zo, H. (2017). User acceptance of media tablets: an empirical examination of perceived value. Telematics and Informatics, $34(4), 206-223$

Wu, L. H., Wu, L. C., Chang, S. C. (2016). Exploring consumers' intention to accept smartwatch. Computers in Human Behavior, 64, $383-392$. http://www.portal.euromonitor.com/portal/statisticsevolution/index 